\title{
What men and women think while watching the news: An exploration
}

\author{
PAUL G. HENDRIKS VETTEHEN, GABI SCHAAP \\ and SOLANGE SCHLÖSSER
}

\begin{abstract}
This study addresses gender differences in television news processing. Male and female subjects were asked to verbalize their thoughts while they watched an edited television newscast. The authors use an interpretive procedure to analyze both the newscast's content and protocols of the thoughts expressed by the subjects. Results indicate that women and men differ in the number and types of thoughts they have while watching the news. Most notably, the analyses suggest that women generally experience a lack of information while they watch newscasts that can be regarded as largely masculine in nature. This perception of not being informed culminates in criticism of the news among the highly educated women while it causes embarrassment among the lower educated women. The consequences of the findings and possible uses of the method for future news research are discussed.
\end{abstract}

Keywords: Television news, interpretation, thought-listing, gender differences, news content

\section{Introduction}

Equal access to information about public affairs for all citizens is generally considered of vital importance in a democratic society. Citizens should have sufficient and balanced information about public matters in order to be able to participate in the democratic process. The mass media play a key role in this process; for the average citizen the media are the only means for obtaining information about public affairs and other events with which they do not have direct experience. Since the beginning of television broadcasts, television news has been a primary source for this type of information. Many citizens in western societies see it as their duty to be well-informed about public affairs. They consider televi- 
sion to be a highly reliable source of information, and, therefore, watch the news on a daily basis (Gunter, 2001; Gunter and Winstone, 1993; Hagen, 1994; Robinson and Davis, 1990). Additionally, politicians perceive television news as important, because they consider it a valuable tool to influence public opinion and convince potential voters of their viewpoints (cf. Oegema and Kleinnijenhuis, 2001).

Despite the popularity of television news with the general populace, there has been a fair amount of criticism. For instance, television news content has been criticized for reflecting only the concerns of the most powerful developed countries (MacBride, 1980; Roe, 2001; Wallis and Baran, 1990). McManus (1994) even urges western citizens 'to beware of' the news, as it is said to be biased in favor of the interest of the market.

The starting point for the present study is another critical observation. Television news is frequently seen as a 'masculine' genre in that it is made by (middle aged, middle class) men, especially for these men, and that it is largely about men. This criticism is based on two observations. First, the journalistic profession is notorious for being a traditional 'male territory'. Female journalists are underrepresented in television news (as are other social strata, such as ethnic minorities); roughly only one third of the television journalist corps consists of women (Carter, Branston, and Allen, 1998; Klite and Bardwell, 1997). Although in recent years, women journalists seem to be closing this gap, they still remain a minority in the middle and higher echelons of television news rooms (Becker, Lauf, and Lowrey, 1999; Deuze, 2002; Hermans, 2000). Moreover, as a rule, male journalists cover the most prestigious items, and $73 \%$ of the sources used by both male and female journalists is male (Cann and Mohr, 2001; Liebler and Smith, 1997; Soderlund, Surlin, and Romanov, 1998; Zoch and VanSlyke Turk, 1998). These facts have led noted feminist author Naomi Wolf to dubbing television the 'boobless tube' (Wolf, 1998).

Second, both this male dominance in the newsroom and the news is reflected in the world view with which the news audience is presented. The news, some argue, is directed by a masculine view of the world: "It is in the definition of newsworthiness, particular angles and styles, professional norms and values that the masculine nature expresses itself" (Carter et al., 1998: 35). A 1995 international UNESCO study, for instance, revealed that only $1.4 \%$ of television news items specifically deal with women's issues. If women or women's issues are shown in the news, women are stereotypically portrayed as victims or in traditional 'women's roles' such as mothers, wives, and caretakers (Greco Larson, and Bailey, 1998; cf. Gallagher, Spears, and Seydegart, 2000; Zoch and VanSlyke Turk, 1999). 
Public discussions about news reflect the masculine nature of news. Van Zoonen (1991) notes that in the public debate, tendencies towards more 'humanized' news presentation, which is often equated with 'feminine' news presentation, are heavily criticized. News, according to many, should be 'objective', rational and distant; not intimate, emotional and human. It is, in other words, supposed to be masculine.

\section{Research question}

The presumed masculinity of television news raises a question about its significance for women. Research on the processing of television news underlines the importance of this question. Regardless of a few exceptions (e. g., Peeters and Heuvelman, 1996), these studies show that men remember more of television news than women do, while some studies have found evidence that women do not understand as much of the news as men do (cf. Brosius and Berry, 1990; Findahl and Höijer, 1985; Giegler and Ruhrmann, 1990; Gunter, Furnham, and Gietson 1984; Hendriks Vettehen, Hietbrink, and Renckstorf, 1996; Renckstorf, 1980; Robinson and Levy, 1986).

Of course, attempts have been made to explain these findings. Usually, the origins of retention and comprehension differences are sought in social characteristics of the female television news viewer. Women remember relatively little from the news because, on average, they are lower educated and have insufficient background knowledge to process news items (Hendriks Vettehen et al., 1996; Peeters and Heuvelman, 1996). Furthermore, they find the news less relevant or interesting (Biswas, Riffe, and Zillmann, 1994; Jensen, 1986, 1988; Morley, 1986), and consequently, they pay less attention to it (Konig, Renckstorf, and Wester, 1998).

Hendriks Vettehen and Schaap (1999: 231) offer an additional explanation for the relatively poor performance of women on recall tests, arguing that "measurement is also limited to the (often male) researcher's estimation of what the (also often male) journalists would consider to be the 'gist' of the message". Most researchers as well as journalists take the (masculine) canons on what does and what does not constitute 'news' as fixed rules. Consequently, traditional recall measures have concentrated on the recollection of specific news facts (e.g., Who? What? Where? When?) (Robinson and Davis, 1990), that could be of interest to primarily the male news viewers, thus explaining the relatively poor performance of women on recall tests. Hendriks Vettehen and Schaap suggest a more 'audience centered' measure of recall; this could provide a more complete picture of news processing than traditional recall measures do, at least as far as gender related differences in recall are con- 
cerned. When, instead of adopting a journalist/researcher's point of view, the viewer's personal notions and interpretations of 'news' are considered relevant, we might get a richer picture of how viewers make sense of the news.

In sum, previous research has primarily documented what women are not doing while watching the news; they are not processing and storing information in the way researchers and journalists would like them to, or, in this respect, in the way men do (cf. Giegler and Ruhnrmann, 1990; Gunter, 1987; Stauffer, Frost, and Rybolt, 1986). It has also provided some hypothetical explanations. However, very little attention has been paid to the question what women are doing while watching the news. Do they really understand the news not as well as men do? What do they want from news? How do they make sense of it? What do they think while watching the news? In other words, what do they 'get' from the news? The present study aims at answering this question.

\section{Method}

\section{Design}

The exploratory character of this study is represented by two factors. First, we used a limited number of subjects $(\mathrm{N}=19)$, whose thoughts while watching a newscast were studied intensively. The sample consisted of 10 women and 9 men. They were selected to include a variety of ages and educational backgrounds. Second, we recorded their thoughts about not more than one newscast, which consisted of seven news items (the Dutch NOS 8 o'clock newscast of Tuesday 21 November, 2000).

To check whether this particular stimulus broadcast could be considered as 'masculine' as the average newscast, we analyzed the transcribed text and images of the newscast, using three rough indicators of 'masculinity', that is, the number of female actors, the roles in which they appeared and the type of issues that were covered in the news items (cf. Gallagher et al., 2000; NOS / Meer van Anders, 2002). Our analysis revealed three things. First, women were virtually absent as central actors in all news items save one. In this one item, concerning BSE, the representation of men and women was more or less equal; all central actors in this item were politicians. In contrast, 17 men were present in the other seven items as central actors, either as politicians, experts or celebrities. No 'ordinary' person (man or woman) appeared on the program. Finally, three male reporters and one female reporter contributed to the program. A male anchor presented the program.

Three out of eight news items dealt with foreign politics. In addition, a number of items contained references to violence. One of the foreign 
news items contained footage of four male politicians as well as footage of violent clashes between Palestinian youth and Israeli soldiers; another one contained footage of a military parade inspected by former Iraqi leader Saddam Hussein; the third contained footage of a conference room with men watching former Yugoslavian president Slobodan Milosević on a television screen. Because of the (threat of) violence and the prominence of politics and the omnipresence of men in these three items, these items could be considered typical examples of 'news concerning men'. One additional foreign news item reported the collapse of an apartment block in Germany, resulting in several deadly casualties. Two other items concerned economic and social problems in The Netherlands (political disputes on BSE and euthanasia). The remaining two items fell in the category of 'human interest'; they reported on an exhibition and on a Dutch drama series about an amateur soccer team winning an Emmy Award.

From these findings we can conclude that the news program watched by our subjects does not diverge from the average news program as described in previous studies. In the very least it could be argued that this program contains news by men and about men and that it, therefore, can be regarded as average news for men.

\section{Data gathering}

We used an interpretive method designed to generate verbalizations of thoughts known as 'Thought-Listing Technique', to measure what it is viewers 'do' inside their heads while they watch the news. This technique originated in cognitive psychology to 'measure' what people think while performing certain tasks (e.g., solving a mathematics problem). Within this specific discipline, this technique's theoretical basis has been well established and its validity has been widely tested (cf. Cacioppo, Von Hippel, and Ernst, 1997; Davison, Vogel, and Coffmann, 1997).

The use of the Thought-Listing Technique is based on assumptions from the information-processing theory that the information stored in one's short-term memory is not only easily accessible, but can also be verbalized without great effort (Ericsson and Simon, 1984; Green and Gilhooly, 1996). Short-term memory consists of highly accessible information that is 'kept at hand' for immediate usage, as well as links to long-term memory with its vast amounts of relatively permanent information (Ericsson and Simon, 1984; Fiske and Taylor, 1991; Green and Gilhooly, 1996; Van Someren, Barnard, and Sandberg, 1994). The Thought-Listing Technique aims to obtain a picture of the information 
existent in one's short-term memory in a given period. As Schaap (2001) has shown, the technique can be applied to examine what people think while they are watching television news. In the present study, we also applied this procedure.

A program with a running time of approximately 21 minutes was edited into segments, adding breaks (a few seconds of black screen) between them in which the researcher would stop the tape. The segments were edited in such a way that they represented a time-span that was neither too long nor too short, and that they were divided into more or less 'natural units' (for instance, no cuts in mid-sentences, or unnatural shifting of images). This was done in order to facilitate the retrieval of thoughts from short-term memory, before they were 'lost' in the longterm memory. This resulted in a segmented news program of 24:16 minutes (including spaces between the segments), consisting of 67 segments with an average length of approximately 18 seconds, the longest segment running 27.4 seconds and the shortest 7.2 seconds.

Generally, the subjects participated in the verbalization task at home, with the exception of a few who watched the program in a viewing room at the University of Nijmegen, The Netherlands. They were provided with specific instructions to verbally list their thoughts after each segment, as soon as the screen turned black, emphasizing that they be as complete as possible and that no thoughts would be considered 'right', 'wrong' or 'irrelevant'. The subjects were given as much time as they needed to verbalize their thoughts. In addition, subjects were requested not to value, justify or explain their thoughts in order to prevent rationalization of these thoughts.

Immediately after the subjects finished verbalizing their thoughts on one news segment, the newscast continued. During the verbalizing phase, the researcher used an observation sheet with a transcription of the text and images of the news program to make notes of the subject's behavior, which were used in interviews conducted afterwards. The verbalizations were recorded using a tape recorder. We used the first item in the news for the subjects to 'practice', to ensure that the subjects understood what was expected of them, and felt comfortable about completing this task (cf. Green and Gilhooly, 1996; Van Someren, Barnard, and Sandberg, 1994). This first item was not included in the analysis.

After watching the news, the subjects were interviewed, watching the tape again if they needed a cue to remember what they thought during certain parts of the news. The interview was intended to clarify uncertainties, for instance, sounds or expressions which the interviewer did not understand, or moments when subjects did not say much. 
Analysis

Analysis of the material was conducted in two steps. First, different types of verbalized thoughts were conceptualized. Second, the frequency with which these different types of thoughts occurred among women and men was analyzed.

Conceptualization of different types of thoughts. The coding and analysis of the transcribed protocols involved an iterative process of careful reading, conceptualizing of different types of thoughts and subsequent rereading of the material (cf. Miles and Huberman, 1994; Wester, 1987). First, each protocol was subdivided into smaller segments. A segment consisted of one 'meaningful unit', that is, one separate distinguishable argument or line of reasoning, used by the subject (in other words; one 'thought').

Subsequently, after reading a segment, a label was assigned to it, including a short description of its contents. These labels were then categorized to construct a basic classification of similar segments by further reading of the segments. After repeatedly re-reading, re-labeling and recategorizing, we arrived at a classification of 399 verbalized thoughts by 19 subjects into seven concepts or 'types of thoughts'. These concepts were 'expressing an opinion' (coded 166 times), 'empathy' (54), 'showing insight into choices made by actors' (25), 'showing signs of being distracted from the news' (47), 'expressing a lack of (clear) information' (46), 'criticizing news coverage' (46), and 'expressing disinterest in a specific news item’ (15).

The search for differences between the thoughts of women and men. In the final analytical step, we searched for differences in the frequency with which women and men used each of the seven concepts in their thinking while watching the news. For us to obtain a more complete picture, our analysis not only focused on gender, but also on educational level and occupation. Due to the small and non-representative sample any differences found could not be tested for significance.

\section{Findings}

In a number of instances, specific categories of viewers displayed distinct thoughts on the news items. In the following section, we will focus on the main, gender-related, differences (see table 1).

One difference between the thoughts of men and women on the news was that our female subjects showed considerably more 'empathy' with people or situations in the news than their male counterparts. One female subject provides a typical example of this type of thought (all following quotations are translated from Dutch): 
Table 1. Number of different thoughts while watching TV news by gender and education*; means (absolute frequencies) $(n=19)$.

\begin{tabular}{|c|c|c|c|c|c|c|c|}
\hline & \multicolumn{2}{|l|}{ Women } & \multirow{2}{*}{$\begin{array}{l}\text { Women } \\
\text { Total } \\
(\mathrm{n}=10)\end{array}$} & \multicolumn{2}{|l|}{ Men } & \multirow{2}{*}{$\begin{array}{l}\text { Men } \\
\text { Total } \\
(\mathrm{n}=9)\end{array}$} & \multirow{2}{*}{$\begin{array}{l}\text { Total } \\
(\mathrm{n}=19)\end{array}$} \\
\hline & $\begin{array}{l}\text { Low } \\
\text { educa- } \\
\text { tion } \\
(\mathrm{n}=6)\end{array}$ & $\begin{array}{l}\text { High } \\
\text { educa- } \\
\text { tion } \\
(n=4)\end{array}$ & & $\begin{array}{l}\text { Low } \\
\text { educa- } \\
\text { tion } \\
(\mathrm{n}=6)\end{array}$ & $\begin{array}{l}\text { High } \\
\text { educa- } \\
\text { tion } \\
(\mathrm{n}=3)\end{array}$ & & \\
\hline $\begin{array}{l}\text { Expressing } \\
\text { an opinion }\end{array}$ & 10.0 & 12.0 & 10.8 & 7.7 & 4.0 & 6.5 & 8.7 \\
\hline $\begin{array}{l}\text { Insight into } \\
\text { choices }\end{array}$ & 1.0 & 1.5 & 1.2 & 1.7 & 1.0 & 1.5 & 1.4 \\
\hline Empathy & 3.3 & 4.8 & 3.9 & 1.8 & 1.3 & 1.6 & 2.8 \\
\hline $\begin{array}{l}\text { Expressing } \\
\text { disinterest }\end{array}$ & 1.3 & 0.8 & 1.1 & 0.3 & 0.7 & 0.4 & 0,8 \\
\hline $\begin{array}{l}\text { Signs of } \\
\text { distraction }\end{array}$ & 1.0 & 4.0 & 2.2 & 1.7 & 5.0 & 2.8 & 2.5 \\
\hline $\begin{array}{l}\text { Lack of (clear) } \\
\text { information }\end{array}$ & 2.7 & 4.8 & 3.5 & 1.2 & 2.3 & 1.6 & 2.6 \\
\hline Criticism & 0.0 & 8.8 & 0.9 & 0.2 & 3.3 & 1.2 & 1.0 \\
\hline $\begin{array}{l}\text { Total } \\
\text { (number of } \\
\text { thoughts) }\end{array}$ & $\begin{array}{l}18.8 \\
(113)\end{array}$ & $\begin{array}{l}36.5 \\
(146)\end{array}$ & $\begin{array}{l}25.9 \\
(259)\end{array}$ & $\begin{array}{l}14.5 \\
(87)\end{array}$ & $\begin{array}{l}17.7 \\
(53)\end{array}$ & $\begin{array}{l}15.6 \\
(140)\end{array}$ & $\begin{array}{l}21 \\
(399)\end{array}$ \\
\hline
\end{tabular}

* Low education $=$ higher vocational education and lower, High education $=$ bachelor's degree and higher

It almost makes me cry when I see this. It won't stop there; no it won't ... a terrible sight! Often when [the news] is on, I turn it off. I just switch to another channel. I just can't stand seeing this ... The Arabs, yes, it makes me feel bad when I see this.

The fact that women's thoughts show more signs of empathy may be interpreted by examining the news content. As described earlier, a number of items dealt with a potentially emotion-evoking theme: death and violence. Besides items with stories and images of violence, one item, concerning the 'mad cow disease', actually contained footage from an abattoir. Items like these can be considered emotion-evoking. Höijer (1996) also found women to differ from men in their responses to emotional news items. She notes that while the different gender roles encourage women to empathize with emotional situations, most notable violent situations, it is a specifically male characteristic to "steel themselves to protect themselves against the myth of violence" (1996: 58). In other 
words, men ward off emotional reactions to potentially emotional news, while women empathize. A second gender-related difference in thoughts we found concerns the by far most popular verbal activity of both genders: expressing personal opinions on issues or persons in the news. The length of thoughts of this type varied greatly. At times they included elaborate argumentations, at other times they were limited to short statements of agreeing or disagreeing. One possible explanation for the prominence of personal opinions in thinking about the news is that, as stated earlier, the news is often watched because people feel obliged to stay informed or construct opinions on public issues. A news program, with its emphasis on real life situations and on controversy, stimulates viewers to reflect on and form opinions about these topics.

Although both genders expressed a relatively large number of personal opinions, we found an interesting difference between women and men. Highly educated women expressed their opinions somewhat more often than average, whereas highly educated men expressed their opinions considerably less than average (see table 1). At first glance, we assume that subjects with a higher level of education possess more background knowledge about public issues, which in the news program were all covered at the rather abstract level of politics and specialists. This background knowledge allows them to reflect more easily on these matters, and thus to express their opinions about them. Alternatively, among highly educated people expressing opinions about current affairs may be regarded as having more social value than is the case for lower educated groups.

However, if education were the only factor influencing the expression of personal opinions, we should find that both highly educated men and women express opinions more frequently than their lower educated counterparts. As said, this was, in fact, not the case, and a second factor seems to influence the utterance of opinions. All three highly educated men in our sample were employed in positions requiring higher education, whereas the highly educated women were either unemployed or held an occupational position that required little or no education. We assume this difference in occupational position accounts for the relatively small number of expressed personal opinions among the highly educated men. The professional position of highly educated men might require them to constantly formulate opinions during the workday, leaving them less inclined to do the same while watching the news in what they consider leisure time. Alternatively, or perhaps additionally, the often responsible occupations could have taught them to 'bite their tongue'. 


\section{Criticism and embarrassment among female viewers}

The most striking results in regard to gender differences in thinking about news concerned the concepts 'expressing a lack of (clear) information' and 'criticizing the news coverage'; 'expressing disinterest in a news item'; and 'showing signs of being distracted from the news'. These findings did not only concern differences between men and women, but also differences among women.

In the introduction, we referred to findings from studies on news recall indicating generally low levels of recall among women. Our analyses revealed some additional results that relate to this issue. Most notably, during the newscast women complained twice as often as men about the insufficiency or the lack of clarity of the information presented in the news (table 1). Some women (often the highly educated) expressed a lack of contextual information, as illustrated by one woman's thoughts on the item about the 'mad cow disease':

Eh, what's [the minister of agriculture] doing with the meat we consume? What's the situation now? How are they going to cope with it? ... I still wonder how he's going to deal with it, why it will be all right. How did he arrive at that conclusion? What is it based on? Eh, will those measures do? Well, I doubt whether they will suffice ... is that possible?

To other women the information presented was often not so much lacking, as it was unclear. In other words, they did not seem to understand the message, as one of them expressed in a few words:

\section{I don't understand what this is all about.}

At first sight, these types of reactions may be hardly surprising in the context of the notions concerning the masculine nature of television news we described above. Women could be less familiar with the masculine world presented in the news, they could be less interested in this type of news and they could be less concentrated while watching the news. As a result, they miss out on some of the information, and subsequently feel that they are badly informed. However, the analyses appeared to produce a more complex picture, as the highly educated women showed a different thought pattern than the women of lower education. The four highly educated women together produced a total of 35 thoughts that can be considered critical of the news. In contrast, the three highly educated men produced only 10 of these critical thoughts, whereas the six lower educated men produced just one critical thought and the six lower educated women did not produce one single 
critical thought. The nature of the critical thoughts varied. Some women expressed doubts about the usefulness of some of the information presented, as expressed by this female subject:

Well, the fact that they had a meeting doesn't have any news value to me. Why do I have to know about this? [...] I mean, what's the use of this?

Some women also felt that some of the news stories were fabrications or at least biased, as illustrated by the following statement on an item about euthanasia:

Well, I just don't believe this [...] well, I think this is a very biased report, I am very displeased with the news broadcasting such a story ... where does this nonsense come from?

These findings could be explained by a similar theory we applied to explain differences in the numbers of expressed opinions; a higher educational level stimulates critical thinking about the newscast, while the nature of men's occupations leaves them less willing to express these criticisms. However, here, we would like to suggest a slightly different interpretation, to better account for the finding that our female subjects more often express the feeling that the information they receive is insufficient than the male subjects. Our theory suggests that the higher educational level of both women and men could stimulate critical thinking about the newscast. However, the highly educated women might have more reason to be critical than the highly educated men, simply because women feel they are not sufficiently informed. This seems quite reasonable, given the male-directed character of the newscast. In short, these highly educated women attribute the lack of information they experience to the program; that is, they feel it does not provide them with enough useful information, and as a result they get irritated.

None of the six lower educated women expressed a single critical thought about the news. We think that, because of their lower educational level, these women were less inclined to attribute the lack of clarity of the information to the program. Instead, they seemed to blame themselves. Indicative of this was the finding that lower educated women were the only subjects who frequently stated explicitly that they were not interested in a news item. In the words of one of them:

Politics, no that's not my cup of tea.

However, some additional results give us reason to question whether these women were actually disinterested. First, in sharp contrast to their 
expressions of disinterest, the lower educated women showed considerably less signs of distraction from the news content. The other subject groups did show signs of being distracted, such as associating parts of the news with matters that were not directly or indirectly related to the news content. Second, with the sole exception of the above quotation, all women used the Dutch word 'eigenlijk' when expressing their disinterest. The word is difficult to translate, but in this case, 'eigenlijk' is used as a disclaimer; these women used the word to express their own insecurity. These lower educated women are not used to reflect critically on phenomena such as newscasts. Lacking alternative explanations for their feelings of not being informed or for not understanding, they had no alternative but to blame themselves. What they felt while watching the newscast was plain embarrassment. The only way out of this conclusion was stating that they were 'eigenlijk' not interested in the news. The fact that the woman quoted above provided the only example of stating her lack of interest without this disclaimer further strengthens our doubts about the apparent disinterest in the news among the lower educated women.

It is interesting to note that, despite frequently expressed critical attitudes towards news framing and journalists' news values, none of the women (nor the men, for that matter) ever explicitly mentioned the masculine character of the news. Although this may seem odd, theoretical notions concerning concepts of 'ideology' or 'myth' maintain that the dominant culture will hardly ever be questioned because of its power to present its sense of events as the 'natural' way of perceiving them (cf. Fiske, 1987). With this in mind, the absence of explicit criticism of the masculine character of the news should not be surprising, even though a number of women express a sense of discomfort with the news.

Summarizing, our interpretation of the findings suggests that television news does not succeed in providing women with clear information about the things they think are relevant. The result is a predominantly critical attitude among the highly educated women, and embarrassment among the lower educated women.

\section{Conclusions and discussion}

Many previous studies on news processing have suggested that, influenced by various factors, women do not seem to be as busy or effective as men are in processing and storing journalistic 'news facts'. The purpose of this study was to add some insights to this picture by investigating what women actually $d o$ in their minds while watching the news. Do they really differ from men in how they watch the news? 
Our analysis suggests that there are indeed various differences in the way the two genders make sense of the news. In short, women's thoughts seem to indicate more emotional involvement in the news than men's thoughts, and highly educated women with no professional occupation express more opinions about the news than highly educated men in highlevel jobs. Most importantly, however, women experience a lack of information or a lack of clear information, a finding we interpreted as resulting from the newscast's 'masculine' character. This feeling of not being informed culminates not only in frequently not understanding the news, but also in either criticism among highly educated women, or embarrassment among lower educated women. From these results, we conclude that large portions of the female audience probably do not 'get' what they want from television news. They are not informed about the issues they consider interesting and important, simply because television news seems to be designed to inform men, and not citizens in general.

Of course, one should not regard this gloomy conclusion as definitive, given the small number of cases, the lack of a 'feminine news' condition in our research design, and the high level of interpretation upon which the analyses relied. Our conclusions should be regarded as tentative. If, however, they prove to be true in future research, it should give rise to serious concerns about the role of television news in democratic societies.

Unfortunately, finding a remedy may not be easy. For instance, although we concur with the often-heard appeal to newsmakers to increase the role of women in television news production, there is reason to assume that such a policy alone will not have many beneficial effects. The canons of journalism, concerning 'newsworthiness', 'objectivity', and what constitutes 'good' news in general, in which both male and female journalists have been socialized in their profession, could very well prevent them from moving towards more 'feminine' news (cf. Zoch and VanSlyke Turk, 1999). Consequently, it is the currently prevailing journalistic culture that should be a prime target for changes. Especially among our future journalists, stimulating the debate concerning the gendered nature of news is the least that should be done.

Some final remarks can be made on the significance of this study for future television news research. Much television news research is rooted in cognitive psychology, applying concepts from information processing theory to study recall and comprehension of television news items (cf. Findahl and Höijer, 1985; Giegler and Ruhrmann, 1990; Robinson and Davis, 1990; Woodall, Davis, and Sahin, 1983). Theory and research within this tradition have resulted in a better understanding of how people remember and understand the news (Berry, 1983; Woodall, Davis, and Sahin, 1983). It can be concluded that watching the news is regarded as a complex process in which the viewer stores information and uses 
previous knowledge to make inferences, possibly leading to deformations in the information.

Notwithstanding these progressive insights, this line of research has been criticized for founding their research solely on the researcher's or journalist's assessment of what is important to remember or correct to understand (Robinson and Davis, 1990). Critical communication research (cf. Jensen, 1986, 1988) and interpretive theories (cf. Al-Menayes and Sun, 1993; Renckstorf and Wester, 2001) maintain that what viewers do with the news, should not (only) be studied from the point of view of the researcher or the journalist, but (also) from the position of the viewer. Research should not confine itself to searching for 'effects' in the way the journalist has intended them, such as the correct remembrance of facts, represented by institutionalized journalistic questions. Instead, the 'reconstruction', or 'meaning' that is relevant to the viewer should be studied. Picture for instance an item on a bombing raid in Iraq. From the journalist's point of view, respondents should remember that the bombing took place in $\mathrm{Al} \mathrm{Qud}$, involving 18 Iraqi civilians and 21 American airplanes. But, critics maintain, who is to say that viewers who remember mainly that there was tremendous human suffering somewhere did not remember the message 'correctly'; who is to judge which interpretation of this event is more 'true'? As traditional recall measures do not account for these differences between journalists and viewers and as a consequence are only able to obtain a very fragmented idea of what happens with a message inside the viewers' heads, it is necessary to study the way people 'deconstruct' or 'interpret' the message. Research of this type has already shown that news viewers do indeed interpret news items in their own terms. They use their own meaning categories to make sense of news content that do not necessarily conform to the categories used by journalists (cf. Jensen, 1988).

This study could be regarded as an illustration of how an alternative way to observe the 'processing' of news can supplement results of earlier research in this field. Our analysis of verbalized thoughts suggests that news viewers do indeed interpret information in a way that can both be divergent from the journalist's intentions and expectations, and go beyond the researcher's recall measures. Viewers can disagree with the news, become emotionally involved, link news events to entirely different matters, or criticize news coverage. Perhaps, in future research similar findings can help understand recall and comprehension levels found in earlier research.

Further research could include the Thought-Listing Technique method in different research settings, for instance by varying news content, formal features, or social groups. Thus new hypotheses could be developed 
and tested, for instance on the types of meanings attached to the news, as well as on the ways in which these types of meanings relate to characteristics of the viewers and to features of television news.

\section{References}

Al-Menayes, J. J. and Sun, S. W. (1993). Processing complex information. What are cognitive units and how are they related? Gazette, 52, 57-84.

Becker, L. B., Lauf, E., and Lowry, W. (1999). Differential employment rates in the journalism and mass communication labor force based on gender, race, and ethnicity: Exploring the impact of affirmative action. Journalism and Mass Communication Quarterly, 76(4), 631-645.

Beentjes, J. W. J. and Van Vlijmen, J. (2001). Children's understanding of television news. In K. Renckstorf, D. McQuail, and N. Jankowski (Eds.), Television news research: Recent European approaches and findings (pp. 221-230). Berlin: Quintessence.

Berry, C. (1983). Learning from television news: A critique of the research. Journal of Broadcasting, 27(4), 359-370.

Biswas, R., Riffe, D., and Zillmann, D. (1994). Mood influence on the appeal of bad news. Journalism Quarterly, 71(3), 689-696.

Brosius, H. B. (1989). Influence of presentation features and news content on learning from television news. Journal of Broadcasting, 33, 1-14.

Brosius, H. B. and Berry, C. (1990). Ein drei Faktoren Modell der Wirkung von Fernsehnachrichten. Media Perspektiven, 9, 573-583.

Cacioppo, J. T., Von Hippel, W., and Ernst, J. M. (1997). Mapping cognitive structures and process through verbal content: The thought-listing technique. Journal of Consulting and Clinical Psychology, 65(6), 928-940.

Cann, D. J. and Mohr, P. B. (2001). Journalists and source gender in Australian television news. Journal of Broadcasting and Electronic Media, 45(1), 162-174.

Carter, C., Branston, G., and Allan, S. (1998). News, gender and power. London: Routledge.

Davison, G. C., Vogel, R. S., and Coffman, S. G. (1997). Think-aloud approaches to cognitive assessment and the articulated thoughts in simulated situations paradigm. Journal of Consulting and Clinical Psychology, 65(6), 950-958.

Deuze, M. (2002). Journalists in The Netherlands: An analysis of the people, the issues and the (inter-) national environment. Amsterdam: Aksant Academic Publishers.

Edwardson, M., Kent, K., Engstrom, E., and Hofmann, R. (1992). Recall immediately following video-change in television news. Journal of Broadcasting and Electronic Media, 4, 395-410.

Ericsson, K. A. and Simon, H. A. (1984). Protocol Analysis. Verbal reports as data. Cambridge, MA: MIT Press.

Findahl, O. and Höijer, B. (1985). Some characteristics of news memory and comprehension. Journal of Broadcasting and Electronic Media, 29(4), 379-396.

Fiske, J. (1987). Television culture. London: Routledge.

Fiske, S. T. and Taylor, S. E. (1991). Social cognition. New York: McGraw-Hill.

Gallagher, M., Spears, G., and Seydegart, K. (2000). Who makes the news. The Global Media Monitoring Project 2000. The World Association for Christian Communication.

Giegler, H. and Ruhrmann, G. (1990). Remembering the news: A LISREL model. European Journal of Communication, 5, 463-488. 
Graber, D. A. (1990). Seeing is remembering: How visuals contribute to learning from television news. Journal of Communication, 40(3), 134-155.

Greco Larson, S. and Bailey, M. (1998). ABC's 'Person of the week': American values in television news. Journalism and Mass Communication Quarterly, 75(3), 487499.

Green, C. and Gilhooly, C. (1996). Protocol Analysis: Practical implementation. In J. T. E. Richardson (Ed.), Handbook of qualitative research methods for psychology and the social sciences (pp. 55-74). Leicester: BPS Books.

Gunter, B. (1987). Poor reception: Understanding and forgetting broadcast news. Hillsdale, NJ: Lawrence Erlbaum.

Gunter, B. (2001). Television news and the audience in Europe: What has been happening and were should we go next? In K. Renckstorf, D. McQuail, and N. Jankowski (Eds.), Television news research: Recent European approaches and findings (pp. 17-46). Berlin: Quintessence.

Gunter, B., Furnham, A., and Gietson, G. (1984). Memory for the news as a function of the channel of communication. Human Learning, 3, 265-271.

Gunter, B. and Winstone, P. (1993). Television: The public's view 1992. London: John Libbey.

Hagen, I. (1994). The ambivalences of TV news viewing: Between ideals and everyday practices. European Journal of Communication, 9, 193-220.

Hendriks Vettehen, P. G., Hietbrink, N., and Renckstorf, K. (1996). Differences between men and women in recalling TV news. In K. Renckstorf, D. McQuail, and N. Jankowski (Eds.), Media use as social action. A European approach to audience studies (pp. 151-162). London: John Libbey.

Hendriks Vettehen, P. G. and Schaap, G. (1999). Sex differences in recalling verbal and visual information from television news. Communications: The European Journal of Communication Research, 24(2), 229-238.

Hermans, L. (2000). Beroepsmatig handelen van journalisten. Nijmegen: Author.

Höijer, B. (1996). The dilemmas of documentary violence in television. NordicomReview, 1, 53-61

Jensen, K. B. (1986). Making sense of the news. Aarhus: University press.

Jensen, K. B. (1988). News as a social resource: A qualitative empirical study of the reception of Danish television news. European Journal of Communication, 3, $275-301$.

Klite, P. and Bardwell, R. A. (1997). Local TV news. Harvard International Journal of Press/Politics, 2(2), 102-113.

Konig, R., Renckstorf, K., and Wester, F. (1998). On the use of television news: Routines in watching the news. Communications: The European Journal of Communication Research, 23(4), 505-525.

Liebler, C. M. and Smith, S. J. (1997). Tracking gender differences. A comparative analysis of network correspondents and their sources. Journal of Broadcasting and Electronic Media, 41, 58-68.

MacBride, S. (1980). Many voices, one world: Towards a new just and more efficient world information and communication order. London: Kogan Page.

McManus, J. (1994). Market-driven journalism: Let the citizen beware. Thousand Oaks, CA: Sage.

Miles, M. B. and Huberman, A. M. (1994). Qualitative data analysis. An expanded notebook ( $2^{\text {nd }}$ ed. $)$. London: Sage.

Morley, D. (1986). Family television: Culture power and domestic leisure. London: Comedia.

NOS / Meer van Anders (2002). Monitor Diversiteit 2002. Hilversum: NOS.

Oegema, D. and Kleinnijenhuis, J. (2001). Personalization in political tv news. A 13wave study to assess effects of text and footage. In K. Renckstorf, D. McQuail, 
and N. Jankowski (Eds.), Television news research: Recent European approaches and findings (pp. 295-310). Berlin: Quintessence.

Peeters, A. and Heuvelman, A. (1996). Is er een zwakker geslacht als het om televisienieuws gaat? Communicatiewetenschap, 24(1), 75-85.

Renckstorf, K. (1980). Erinnerungen von Nachrichtensendungen in Fernsehen (1). Zur Wirkung von Darstellungsformen in Fernsehnachrichten. Berlin: Spieß.

Renckstorf, K., McQuail, D., and Jankowski, N. (Eds.). (1996). Media use as social action. A European approach to audience studies. London: John Libbey.

Robinson, J. P. and Davis, D. K. (1990). Television news and the informed public: An information-processing approach. Journal of Communication, 40(3), 109-116.

Robinson, J. P. and Levy, M. R. (1986). The main source: Learning from television news. Beverly Hills, CA: Sage.

Roe, K. (2001). One planet - one news? A comparison of news coverage by CNN and BBC-World TV. In K. Renckstorf, D. McQuail, and N. Jankowski (Eds.), Television news research: Recent European approaches and findings (pp. 269-277). Berlin: Quintessence.

Schaap, G. (2001). Using protocol analysis in television news research: Proposal and first tests. Communications: The European Journal of Communication Research, 26(4), 443-464.

Schaap, G., Renckstorf, K., and Wester, F. (2001). Three decades of television news research: An action theoretical inventory of issues and problems. In K. Renckstorf, D. McQuail, and N. Jankowski (Eds.), Television news research: Recent European approaches and findings (pp. 47-90). Berlin: Quintessence.

Schütz, A. and Luckmann, Th. (1974). Strukturen der Lebenswelt, Band 2. Frankfurt: Suhrkamp.

Soderlund, W. C., Surlin, S. H., and Romanov, W. I. (1989). Gender in Canadian local television news: Anchors and reporters. Journal of Broadcasting and Electronic Media, 33(2), 187-196.

Someren, M. W. van, Barnard, Y. F., and Sandberg, J. A. C. (1994). The think aloud method. A practical guide to modelling cognitive processes. London: Academic Press.

Stauffer, J., Frost, R., and Rybolt, W. (1986). The attention factor in recalling network television news. Journal of Communication, 4, 29-37.

Wolf, N. (1998). The boobless tube. George, 3(5), 58-60.

Wallis, R. and Baran, S. (1990). The known world of broadcast news. London: Routledge

Woodall, W. G., Davis, D. K., and Sahin, H. (1983). From the boob tube to the black box: Television news comprehension from an information processing perspective. Journal of Broadcasting, 27(1), 1-23.

Zoch, L. M. and VanSlyke Turk, J. (1998). Women making news. Gender as a variable in source selection and use. Journalism and Mass Communication Quarterly, 75(4), $762-775$.

Zoonen, L. van (1991). A tyranny of intimacy? Women, femininity and television news. In C. Sparks and P. Dahlgren (Eds.), Communication and citizenship (pp. 217-235). London: Routledge.

Zoonen, L. van (1997). Feminist perspectives on the media. In J. Curran and M. Gurevitch (Eds.), Mass media and society ( $2^{\text {nd }}$ ed.) (pp. 31-52). London: Arnold. 